\title{
Potential application of the oxidative nucleic acid damage biomarkers in detection of diseases
}

\author{
Cheng Guo ${ }^{1, *}$, Peili Ding ${ }^{1, *}$, Cong Xie ${ }^{1,2}$, Chenyang Ye ${ }^{1}$, Minfeng Ye ${ }^{1,3}$, Chi Pan ${ }^{1}$, \\ Xiaoji Cao ${ }^{2}$, Suzhan Zhang ${ }^{1,4}$ and Shu Zheng ${ }^{1,4}$ \\ ${ }^{1}$ Cancer Institute, Key Laboratory of Cancer Prevention and Intervention, China National Ministry of Education, The Second \\ Affiliated Hospital, Zhejiang University School of Medicine, Hangzhou, Zhejiang 310009, China \\ ${ }^{2}$ College of Chemical Engineering, Zhejiang University of Technology, Hangzhou, Zhejiang 310014, China \\ ${ }^{3}$ Department of Gastrointestinal Surgery, Shaoxing People's Hospital, Shaoxing Hospital of Zhejiang University, Shaoxing, \\ Zhejiang 312000, China \\ ${ }^{4}$ Research Center for Air Pollution and Health, Zhejiang University, Hangzhou, Zhejiang 310009, China \\ *These authors contributed equally to this work \\ Correspondence to: Cheng Guo, email: cheng_guo@zju.edu.cn \\ Xiaoji Cao, email: xiaojicao@zjut.edu.cn \\ Suzhan Zhang, email: zuci@zju.edu.cn
}

Keywords: oxidative DNA damage, oxidative RNA damage, ROS, biomarker, cancer

Received: July 15, $2017 \quad$ Accepted: August 27, $2017 \quad$ Published: September 08, 2017

Copyright: Guo et al. This is an open-access article distributed under the terms of the Creative Commons Attribution License 3.0 (CC BY 3.0), which permits unrestricted use, distribution, and reproduction in any medium, provided the original author and source are credited.

\section{ABSTRACT}

Reactive oxygen species (ROS) are generated after exposure to harmful environmental factors and during normal cellular metabolic processes. The balance of the generating and scavenging of ROS plays a significant role in living cells. The accumulation of ROS will lead to oxidative damage to biomolecules including nucleic acid. Although many types of oxidative nucleic acid damage products have been identified, 8-oxo-7,8-dihydro-2'-deoxyguanosine (8-oxodG) and 8-0xo7,8-dihydroguanosine (8-oxoG) has been commonly chosen as the biomarkers of oxidative damage to DNA and RNA, respectively. It has been demonstrated that oxidative damage to nucleic acid is an initiator in pathogenesis of numerous diseases. Thus, oxidative nucleic acid damage biomarkers have the potential to be utilized for detection of diseases. Herein, we reviewed the relationship of oxidative nucleic acid damage and development of various diseases including cancers (colorectal cancer, gastrointestinal cancer, breast cancer, lung cancer, epithelial ovarian carcinoma, esophageal squamous cell carcinoma), neurodegenerative disorders and chronic diseases (diabetes and its complications, cardiovascular diseases). The potential of oxidative nucleic acid damage biomarkers for detection of diseases and drug development were described. Moreover, the approaches for detection of these biomarkers were also summarized.

\section{INTRODUCTION}

Reactive oxygen species (ROS) are generated continuously during physical and other metabolic reactions in living cells of organism. Superoxide anion, hydroxyl radical, hydrogen peroxide and singlet oxygen are well-known ROS [1]. The endogenous ROS also have important regulatory effect in human signal transduction pathways [2]. Keeping the balance between clearance and generation of ROS plays a critical role in living cells. In human resting state, the antioxidant system of body maintains the redox equilibrium which can remove excess free radicals timely. The antioxidant systems include simple antioxidants such as vitamin $\mathrm{C}$ and $\mathrm{E}$, which can intercept free radicals and prevent cellular biomolecules from damage. Other antioxidant systems are enzymatic systems including superoxide dismutase (SOD), catalase, glutathione peroxidase and others [3]. All these systems 
possess different abilities to limit the concentration of unusual accumulated ROS. When organism is in pathological state or exposed to other precarious exogenous factors, increasing ROS accumulated in vivo, without be removed timely, would lead to a redox imbalance. Its reactive nature can cause extensive oxidative damage to nucleic acid, lipids, and other important cellular structures, leading to cell dysfunctions, metabolic disorders, or even mutations, causing numerous diseases at the end of time [4].

Oxidative damage to nucleic acid can cause base substitution, addition, deletion, and other mutations. During the process of oxidative damage, many nucleic acids oxidized products are generated. 8-Oxo-7,8dihydro-2'-deoxyguanosine (8-oxodG) and 8-oxo-7,8dihydroguanosine (8-oxoG) are predominant ROS-induced oxidative modifiers among different types of oxidative products [5-6]. Herein, we discussed the relationship between oxidative nucleic acid damage and development of various diseases (Figure 1). Then, we described the potential of oxidized biomarkers in diseases detection and drug development. Finally, the approaches for detection of these biomarkers were summarized.

\section{OXIDATIVE NUCLEIC ACIDS DAMAGE}

Hydroxyl radical, as one of the most important reactive oxygen species, plays a vital role in the stress reaction causing damage to nucleic acids and other biomolecules. It can be generated by different mechanisms, for example, undecomposed hydroxyl peroxide parts turning into hydroxyl radical through Fenton reaction $\left(\mathrm{Fe}^{2+}+\mathrm{H}_{2} \mathrm{O}_{2} \rightarrow \mathrm{Fe}^{3+}+\cdot \mathrm{OH}+\mathrm{OH}^{-}\right)$[7]. If accumulated ROS is not scavenged opportunely, redox balance will break up, resulting in the dysfunction of cellular biological detoxification and repair mechanism [8]. Excessive hydroxyl radical attacks adjacent DNA strands which exist not only in cellular but also in mitochondrial, eventually leading to the creation of all kinds of oxidation products [9]. RNA is nearly single strand, and thus the bases can not be protected by hydrogen bonding. In addition, there is also lack of specific RNA protected protein in living cells [10]. Therefore, RNA bases are more susceptible to oxidative damage and oxidative damage to RNA is also accused to hydroxyl radical with the feature of high reactivity and difficult diffusion [11-12]. However, compared with oxidative DNA damage, less effort has been devoted to the investigation of oxidative RNA damage.

The major product of the reaction of 2 '-deoxyguanosine or guanosine with hydroxyl radical is $\mathrm{C} 8-\mathrm{OH}$-adduct radical. Then $\mathrm{C} 8-\mathrm{OH}$-adduct radical loses an electron and a proton to form 8-oxodG or 8-oxoG (Figure 2) [1,13]. 8-OxodG/8-oxoG is the most abundant oxidized products because it is stable and relatively easily formed, though there are other bases reacting with hydroxyl radical in a similar way $[6,14]$.
8-OxodG is cut off from the DNA chain under the effect of a variety of self-protection mechanisms, e.g., base excision repair, mismatch repair and nucleotide excision repair, and then excreted into urine without further metabolism. As a metabolic end product, the level of 8-oxodG is maintained at stable level in vivo fluid and not affected by factors such as diet [15]. However, the mechanism of RNA repair is still not clear and deserved further investigation.

The half-life period of 8 -oxodG is longer than other oxidized products, and it can be easily detected in clinical practice $[16,17]$. 8-OxodG mainly induces the transversion from $\mathrm{GC}$ to $\mathrm{TA}, \mathrm{GC}$ to $\mathrm{AT}$, or $\mathrm{GC}$ to $\mathrm{CG}$, and this is a vital mechanism of ROS induced mutagenesis [14]. Oxidative damage also affected normal function of RNA, including ribosome dysfunction, low translation efficiency and protein synthesis disorders (declining protein synthesis rates, production of aggregated peptides), causing dysregulation of gene expression and errors in key proteins that involved in the chronic-degenerative diseases especially neurodegenerations $[10,11,18]$. Carcinogenesis is a long evolution process of multistage, including DNA mutation, activation of oncogenes and inactivation of tumor suppressor genes, changes of apoptosis regulating genes and DNA repair genes. Mutation is one of the most serious consequences of oxidative DNA damage and it is a critical step in carcinogenesis [19].

\section{POTENTIAL APPLICATION IN DETECTION OF DISEASES}

In previous studies, oxidative nucleic acids biomarkers were considered to be involved in the occurrence and development of different types of cancers, neurodegenerative disorders and chronic diseases (Supplementary Table 1). As shown in this table, oxidative damage exists in various diseases, and the biomarkers are over-expressed in patients compared with controls. Concentrations of oxidative damage biomarkers in patients with diseases are about 1.3 to 5 -fold higher than that in controls. Although there may have some discrepancy in a few studies. This implies that 8 -oxodG/8-oxoG might be a good indicator of diseases and has potential to be a useful clinical biomarker to warn or diagnosis some relevant diseases in the future.

\section{Oxidative damage biomarkers and different cancers}

\section{Colorectal cancer}

As we all know, excessive accumulation of ROS in vivo can cause chronic enteritis, increasing the risk of colorectal cancer especially oxygen-radical-mediated inflammatory colorectal cancer. In organism, many endogenous antioxidant enzymes can defense ROS- 
mediated damage, maintaining the balance of oxidantantioxidant system. 8-OxodG concentrations, glutathione peroxidase, and superoxide dismutase activity sharply increased in plasma from patients with inflammatory bowel disease (IBD) [20]. This may help us to understand why there is a significantly increased risk of colorectal cancer occurrence for patients with IBM, compared to non-IBM. Chang and his colleagues found serum 8-oxodG concentrations highly increased in colorectal cancer patients compared to the control group $(p<0.01)$ [21] Sato et al. measured plasma levels of 8-oxodG from 58 with benign tumor, 32 with early colorectal cancer, 25 with advanced colorectal cancer, 36 healthy controls, and they found that 8-oxodG levels were highest in patients with early cancer [22]. Therefore, we suspect that 8-oxodG could be a potential biomarker for warning colorectal cancer in early stage.

Urine, compared with other biofluids such as plasma and serum, was considered to be a preferred biological matrix in clinical practice since it could be easily obtained in large volumes and it was noninvasive to patients. Recently, we have launched a study involved 142 healthy volunteers and 84 colorectal cancer patients to assess the association between DNA oxidative damage and risk of colorectal cancer [5]. The results show that the levels of urinary 8-oxodG were significantly higher in patients than healthy volunteers. Moreover, for patients with colorectal cancer, the concentration of urinary 8-oxodG elevated gradually from stage I to IV, and the level of urinary 8-oxodG in patients with tumor metastasis was significantly higher than that in patients without tumor metastasis. Another study involved 56 colorectal cancer patients, 72 healthy controls and 15 benign tumor patients revealed that combination of urinary 8-oxoG, 8-oxodG and 5-hydroxymethyluracil had better diagnostic power than alone [23].

There is no specific symptom during early colorectal cancer, just the increased frequency of defecation, constipation, diarrhea, secret anguish. Whereas these symptoms are not representative, most people just take it as general gastrointestinal inflammation. At present, occult blood trails accompany with colonoscopy can highly increase the early detection rate of early colorectal cancer. However, colonoscopy is not pervasive in health examinations due to its high price and poor subjective feeling. Oxidative damage biomarkers could reflect oxidative stress level during the early stage of colorectal cancer. Therefore, 8-oxodG and 8-oxoG might have great potential to be novel biomarkers for detection of colorectal cancer.

\section{Gastric cancer}

The etiologies of the gastric cancer are Helicobacter pylori (H. pylori), geographical environment, dietary habit (including fast eating speed, hot food and salt preserved food), gene and so on. The pathogenesis of many gastric diseases is partly attributed to oxidative damage. H. pylori infection is one of the main risk factor of the gastric cancer. H. pylori induces the inflammation of gastric mucosal barrier, resulting in DNA oxidative damage and accumulation of 8-oxodG. This oxidative damage could be a driving force in the progress from chronic gastritis to gastric cancer [24]. In a recent review, it revealed that oxidative DNA damage to stem cells might play an important role in H. pylori infection-related gastric cancer through chronic inflammation [25]. This indicates that 8 -oxodG might have intimate relationship with occurrence of gastric cancer.

Ni et al. detected 8-oxodG and DNA repair enzymes 8-oxoguanine glycosylase (HOGG1) and Mn-superoxide dismutase (MnSOD) in human gastric mucosa with chronic atrophic gastritis (CAG), gastric cancer (GC) and healthy controls. Compared to the controls, 8-oxodG increased in CAG and GC, but HOGG1 reversed [26]. These data support the hypothesis that 8-oxodG may serve

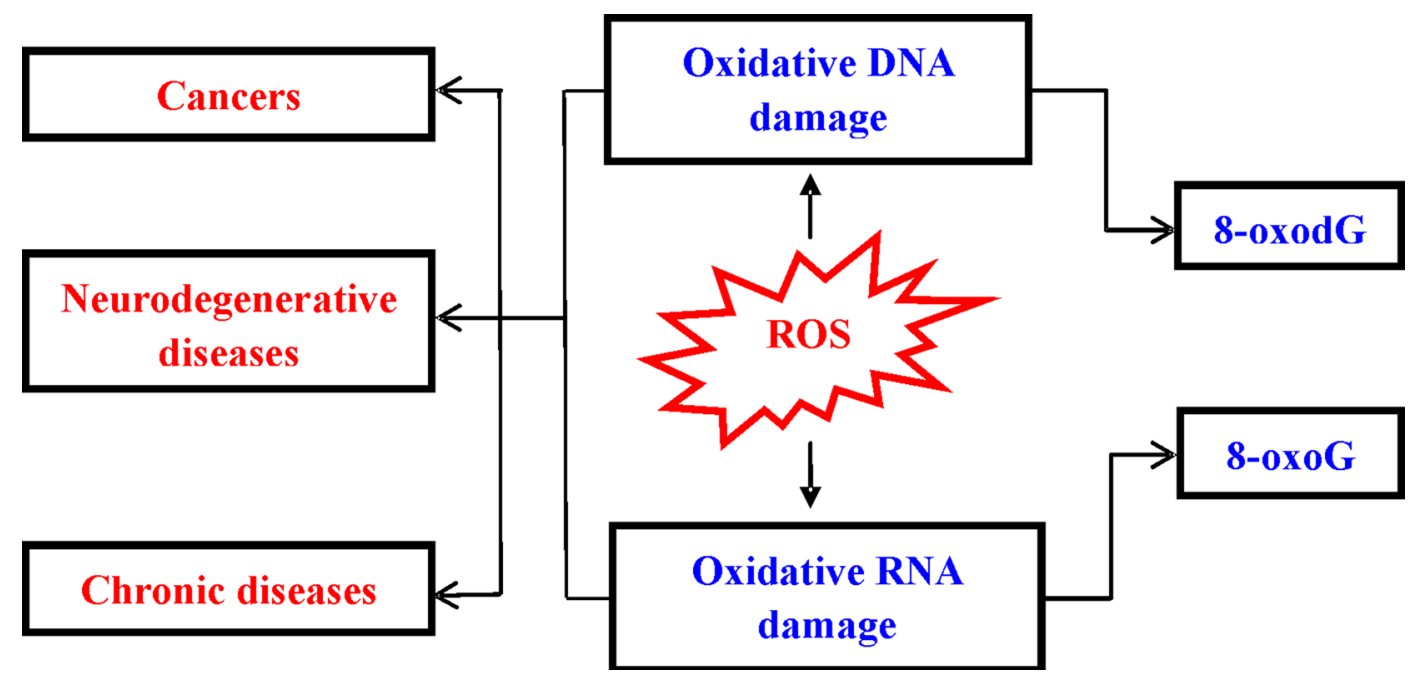

Figure 1: Consequence of ROS-induced nucleic acids damage. 
as a critical risk factor for the occurrence and development of gastric cancer. We should be careful the elevated levels of 8-oxodG in CAG patients and prevent the potentially occurrence of cancer. Kauppi et al. demonstrated that ROS was elevated in the proximal stomach of Barrett's<smiles>Nc1nc2c(ncn2C2CC(O)C(CO)O2)c(=O)[nH]1</smiles>

2'-deoxyguanosine (dG) esophagus and adenocarcinoma patients, which stimulates the proximal stomach mucosa, contributing to the development of cancer in the end [27]. Ma et al. found that the level of 8-oxodG in gastric cancer patients was sharply higher than that in normal [28]. All of these results indicate<smiles>Nc1nc2c(ncn2C2OC(CO)C(O)C2O)c(=O)[nH]1</smiles>
guanosine

(G)

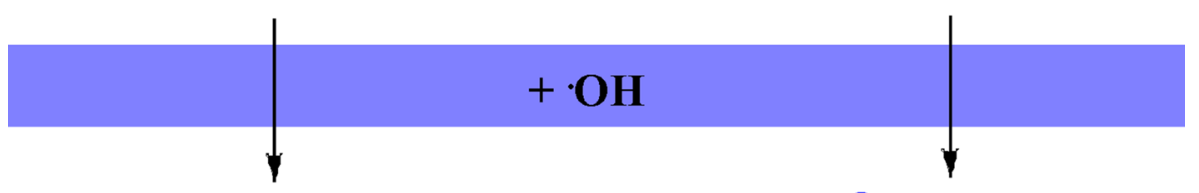

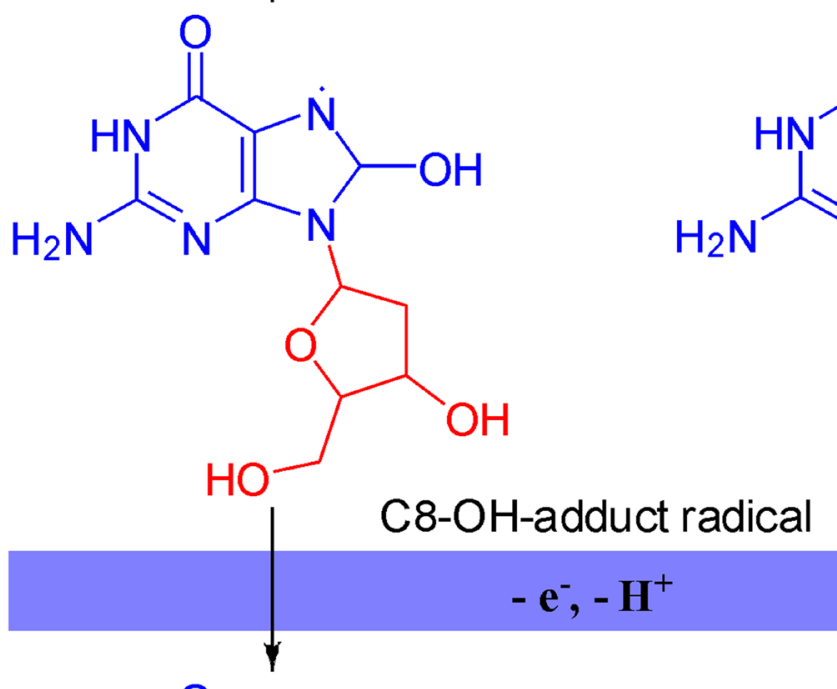<smiles>Nc1nc2c([nH]c(=O)n2C2CC(O)C(CO)O2)c(=O)[nH]1</smiles><smiles>Nc1nc2c([nH]c(=O)n2C2OC(CO)C(O)C2O)c(=O)[nH]1</smiles>

Figure 2: The formation mechanism of 8-oxodG and 8-oxoG. 
that assessing 8-oxodG level may play an important role in early detection and prevention of gastric carcinoma.

Interestingly, it was found that the exogenous 8-oxodG can strangely reduce ROS production, which could be a potential candidate for the treatment of oxygen-radical-mediated gastric diseases and prevention of oxygen-radical-mediated gastric cancer [29]. However, Dincer et al. found that the level of serum 8-oxodG and activity of glutathione were decreased, and superoxide dismutase activity was increased in 19 gastric cancer patients [30]. This results may imply the deficient repair mechanism in cancer patients. Meanwhile, we should get the point that the molecular mechanism of ROS in gastric cancer is still indistinct, and further study still need to be explored.

\section{Breast cancer}

Breast cancer is one of the prevalent cancers in women and known as an estrogens-dependent disease. Oxidative stress is thought to be an important reason for etiology of kinds of cancers, and breast cancer is no exception. Even under normal physical conditions, the damage to DNA is extensive, let alone oxidative stress [31].

In a study involved 150 both pre- and post-operative breast cancer patients, and 150 female controls, urinary 8-oxodG and other nucleic damage products were sharply higher in pre-operative patients than normal controls, and apparently decreased in post-operations [32]. Urinary 8 -oxodG level was found to be higher in the breast cancer patients than that in matched controls [33]. Recently, we have revealed that patients with breast benign lesions could be distinguished from patients with early-stage breast cancer by detection of 8-oxodG in urine [34].

In Sova's study, they analyzed 8-oxodG in serum and tissue from 173 breast cancer patients. Interestingly, the results shown that low 8-oxodG levels both in serum and immunohistochemical expression were associated with an aggressive breast cancer phenotype, especially in ductal carcinomas, and negative 8-oxodG immunostaining was a powerful prognostic factor in breast carcinoma patients [35]. In addition, other research shown that oxidative stress might have less impact in the pathogenesis of triple-negative breast cancer, compared with other types of breast cancers [36]. Nevertheless, DNA oxidative damage biomarker might still be a promising clinical biomarker in the prediction and prognosis for breast cancer patients.

\section{Other cancers}

Oxidative damage also has a clear correlation with the irritation and development of other types of cancer. As we all know, the risk factors of lung cancer are the number of cigarettes per day and the persistent time of smoking.
Some substances of smoke induce lung oxidative stress damage, eventually turning into cancer [37]. Shen et al. demonstrated that patients with higher levels of 8-oxodG had shorter survival time and an over 3-fold increased hazard of death than patients with lower levels [38]. Elevated 8-oxodG in serum or urine was also observed in epithelial ovarian carcinoma (EOC) [39] and esophageal squamous cell carcinoma (ESCC), respectively [40].

\section{Oxidative damage biomarkers and neurodegenerative disorders}

Due to the high energy requirements, high oxygen consumption, and less effective antioxidant systems characteristics, central nervous system can be easily damaged by accumulated ROS [13]. Oxidative nucleic acids damage especially RNA was confirmed closely in touch with the neurodegenerative disorders, such as Alzheimer's disease (AD), Parkinson disease (PD), epilepsy, prion diseases and so on [10]. Oxidized RNA was observed at the earliest-stage of neurological diseases, and promotes the onset and progress of the lesions, which verified by more and more researches on either human or animal models [41].

\section{Alzheimer's disease}

$\mathrm{AD}$ is one of the most common forms of dementia characterized with extracellular senile plaques composed by amyloid-beta. However the concrete etiology of AD is still unclear, oxidative stress might be a crucial contributor to this disease.

In 1999, Nunomura et al. detected the level of 8-oxoG in cytoplasm and nucleoli of neurons of $\mathrm{AD}$ patients and controls. Results showed that its levels were higher in the postmortem brain of AD patients than that of controls [42]. Elevated levels of 8-oxoG were observed in hippocampus from patients with AD [43]. Same result was also found in hippocampus of postmortem brain tissue with $\mathrm{AD}$ [44]. 8-oxoG concentrations were highly increased in cerebrospinal fluid (CSF) of $\mathrm{AD}$ patients [45-46]. Oxidative damage to nucleic acids was identified in neuron of patients with $\mathrm{AD}$ from these studies. 8-oxoG is one of the representative RNA oxidative damage biomarker which can reflect the degree of nerve cells oxidative damage on the other side. The more quantity of the biomarkers be detected, the worse state of the illness.

In the study of oxidative m-RNA damage in $\mathrm{AD}$ patients, m-RNA was heavily oxidized in frontal cortex that normally serves critical physiological functions [47]. And these were found in mild and moderate stage, not end-stage in $\mathrm{AD}$, suggesting that oxidative damage may be a risk factor in the pathogenesis of $\mathrm{AD}$. Ribosomal RNA is one of the abundant molecules in most cells and is affected readily by ROS in human brain. Ding et al. found that oxidized free 5S rRNA might involve in the pathogeny 
of AD [48]. Wang et al. observed the levels of 8-oxoG in mitochondrial were almost 10-fold higher than in nuclear, suggesting that oxidative damage may serve as an etiology of AD [49].

On the whole, oxidative nucleic acids damage might play a significant role in the development of $\mathrm{AD}$ and the level of 8-oxoG increased in patients. If these oxidative biomarkers could be detected sensitively at the beginning of $\mathrm{AD}$, we could take some appropriate treatments (medicine therapy, rehabilitation treatment, and good nursing) to delay further deterioration and progression.

\section{Parkinson's disease}

Parkinson's disease (PD) is also called shaking palsy, a neurodegenerative movement disorder, pathophysiological characterized with Lewy body and selective loss of dopamine neurons, clinical characterized with muscular rigidity, resting tremor, bradykinesia, and postural instability [50].

The level of 8-oxoG in CSF of patients with PD was much higher than that in controls. For patients, 8-oxoG concentration in CSF was highest in the early stage, reduced sharply with the progress of disease [51]. From this, we can get known the possible role of oxidative RNA damage in the occurrence of early stage of PD. Elevated values of 8-oxodG/8-oxoG are commonly observed in CSF of patients with PD and its levels were much higher in female than male patients [52]. This finding in vivo might give us some clues that why $\mathrm{PD}$ diseases progresses is faster in females than males. The 8-oxodG concentration was also increased in urine and serum of 6-hydroxydopamine-lesioned rats (PD model) [53]. There also need some further study to determine how the oxidative nucleic acids damage contributes to the onset and progress of PD. The present investigations show that the level of 8-oxoG increased in the early stage of PD and it could be a preferable clinic biochemical biomarker in detection of PD.

\section{Epilepsy}

Epilepsy is a clinical syndrome characterized with multiply neuron abnormal discharge in highly synchronized way. The pathogenesis mechanism of epilepsy is extremely complicated without completely understanding until now. It afflicts more than 50 million people around the world [13]. The specific etiology and mechanism of epilepsy is still unclear, chronic oxidative stress could cause mitochondrial dysfunction and might play a great role in the pathogenesis of epilepsy [54].

There are some studies to investigate the role of oxidative RNA damage in epileptogenesis. Oxidized RNA was greatly increased in vulnerable neurons of mouse brain after pilocarpine-induced epileptic model [13]. A review article also demonstrated a growth of mitochondrial oxidative stress and subsequent cell damage in body after persistent seizures [54]. Rumià et al. determined several oxidative stress markers in epileptic and non-epileptic humans and found that 8-oxodG concentrations were significantly higher in patients than controls. This was in accordance with the results in animal models, supporting a closely connection between oxidative DNA damage and epilepsy [55]. In a word, a series of results indicate that ROS-mediated damage may be a critical contributing factor to the onset and evolution of seizure-induced neuron degeneration.

\section{Other neurological disorders}

Nucleic acid oxidation damage in neuronal cells was also identified in patients with dementia with Lewy bodies (DLB) [56-57], prion disease [58-59], amyotrophic lateral sclerosis (ALS) [60] and other neurological disorders. Oxidative damage and its products including 8-oxoG were increased in brain tissue with DLB [56-57]. The presence of abnormal protein in prion diseases is connected with a lot loss of antioxidant defense, which contributes to serious neurodegeneration [58]. Several data ascribed the neuron degeneration of prion diseases to oxidative stress, and antioxidant would be a strong potential therapy for these disorders [59]. Oxygen-mediated m-RNA damage occurred in early pre-symptomatic stage was not a consequence of motor dying neurons in patients with ALS, identified that RNA oxidation is an early factor to deteriorate the motor neuron of ALS [60]. What's more, same results were found in multiple system atrophy patients and depressive patients [52, 61].

Currently, researches on nucleic acids oxidative damage in neurodegenerative diseases are still not enough. The role of nucleotides oxidation still need to be further studied, and oxidation products could be expected to be prophylaxis elements in these diseases.

\section{Oxidative damage biomarkers and diabetes mellitus}

Diabetes mellitus is a metabolic disease characterized with hyperglycaemia accused to defects in insulin or insulin disorders. Sustained high blood glucose and chronic metabolic disorders could lead to other tissues or organs damage, dysfunction even failure, especially eyes, kidneys, cardiovascular, and nervous system. Several studies have shown that oxidative nucleic acid damage, mostly oxidative DNA damage are closely contacted with pre-diabetes and newly diagnosed diabetes.

It has been revealed that serum 8-oxodG level was significantly higher in patients with pre-diabetes and was positively relate to body mass index (BMI) [62]. And the concentration was also increased in lean normoglycemic offspring of patients with Type 2 diabetes mellitus (T2DM) [63]. Oxidative stress plays important roles not 
only in T2DM but also in the progress of its complications. 8-OxodG was identified as a useful biomarker in microvascular, macro-vascular, and keratopathy complications of T2DM patients [64, 65].

\section{Oxidative damage biomarkers and cardiovascular disease}

ROS could stimulate muscle growth, media reform, and cells dysfunction by activating cytokinin protease and transcription factors, which has a direct impact on cardiac structure and function [66]. Many researches had identified that 8-oxodG was related to cardiovascular diseases. The 8-oxodG levels in serum and urine increased in patients with coronary artery disease [67-69] and heart failure [68-70]. With elevated 8-oxodG level in body fluid, the severity of coronary artery stenosis increased and heart failure was deteriorated [70]. Thus, properties of 8-oxodG could effectively reflect the heart function and chronic failure status, helping us to assess the clinic cardiovascular disease severity [68, 70-71].

\section{INSPIRATION TO DISEASE TREATMENT AND DRUG DEVELOPMENT}

As we described above, ROS plays an important role in pathogenesis of various diseases. Majority studies have also provided the possible new strategy to treat diseases by using antioxidants or medicine to stabilize the redox signal system. There always need some specific biomarkers to estimate the effective degree of disease treatment in clinic practice. The change of 8 -oxodG or 8-oxoG level is correlated with the oxidative stress in human body, which providing a hot researching spot for medicine development and therapeutic effects.

Among researches of 8-oxodG/8-oxoG represented as oxidative stress level, there are some antioxidants studies [72-77], basic cell trails [78], and more clinical researches. Some studies indicate that antioxidant, just like sesame oil, effectively protected DNA from oxidative damage [72]. Conventional food naturally contains antioxidants and helps to maintain human health and delay disease onset. Khan and his colleagues highlighted the health beneficial effects of the flavonoid antioxidant fisetin which can be found in many fruits and vegetables, such as apple, onion, and so on. It has potential to be a chemopreventive agent against lots of diseases even cancer [73]. Chemopreventive effects of fisetin were identified in several models. However, there also need further in-depth studies to verify the chemopreventive efficacy in vivo as well as other antioxidants. In another study, coenzyme Q10 (CoQ), an additional source of antioxidant in diet, could reduce cellular oxidative progress [74]. Chirayu et al. found that adding antioxidants and polyunsaturated fatty acids as supplements in the treatment of neuropsychiatric disorders, had some promising results [75]. In addition, a review supported the notion that habitual dietary intervention of polyphenols can reduce the risk of lung cancer [76]. However, high-dose antioxidant supplements generally do no good and may cause harm to patients [77, 79]. All of these researches provide us a new hotspot for prevention and treatment of ROS-mediated diseases.

Several studies show that oxidative nucleic biomarkers are correlated with the drug efficacy. 8-OxodG was viewed as one of metabolic parameters to evaluate the effect of bezafibrate and fenofibrate treatments in diabetes [80]. Tissue 8-oxodG level in diabetes rats was significantly lower by treated with insulin and antioxidant, and serum 8-oxoG level was almost normalized by insulin. The result supports the important role of antioxidant (probucol and vitamin E) treatment in the reduction of oxidative stress for the prevention of diabetic vascular complications [81]. However, there also some debates on the association between the glycemic control and level of 8-oxoG and 8-oxodG.

ROS is intimately related with the occurrence of many diseases, and the oxidative nucleic acids biomarkers are frequently used as important biochemical indicators in preventive medicine research, such as cancer protection [82-83], nervous system protection [84-87], improvement of cardiovascular function [88-89], and so on. Along with the increase in drug protection research, 8-oxodG and 8-oxoG are increasingly becoming the focus of drug research in the field of oxidative damage.

\section{DETECTION OF OXIDATIVE NUCLEIC ACID DAMAGE BIOMARKERS}

Quantitative detection of the oxidative damage biomarkers of nucleic acids are mainly through two ways including enzyme-linked immunosorbent assay (ELISA) and chromatography-based techniques (Supplementary Table 1). Due to the simple handing process, ELISA is the most convenient method and has received widespread use, but lack of specificity results in higher value than their real value [90]. Other detection methods are based on chromatography techniques, e.g., gas chromatographymass spectrometry (GC-MS) [91], capillary-electrophoresis with electrochemical detection (CE-ECD) [92], highperformance liquid chromatography with electrochemical detection (HPLC-ECD) [93]. HPLC-MS/MS is of great interest due to its high analytic sensitivity, accuracy and reliability, and it is the mainstream solution for quantitative detection of oxidative damage biomarker in human body fluid and tissue $[5,32,34]$. The sample was pretreated by solid phase extraction (SPE), and then the target analytes were separated by HPLC. Finally, these compounds were detected by mass spectrometer under multiple reaction monitoring mode. With the rapid development of these analytical techniques, evaluation of the potential of oxidative nucleic acid damage biomarkers for detection of diseases becomes more accurate and convenient. 


\section{CONCLUSIONS AND PERSPECTIVES}

More and more researches have demonstrated that increased oxidative damage on nucleic acids directly or indirectly cause dysfunction and detrimental effects to cells, organs and entire body. As the most prevalent oxidative products, 8-oxodG and 8-oxoG could be utilized to estimate the level of intracellular oxidative damage and reflect the internal environment of sick body. Their levels in biofluids or tissue can provide useful and visual messages about morbidity risk assessment, diseases course and therapy effects. 8-OxodG was increased in many different solid cancers and chronic diseases, and 8-oxoG was elevated in neurodegenerative diseases. As we all know, it is difficult to screen disease by only one biomarker. But if we can combine 8-oxodG or 8-oxoG with traditional testing or imaging method, the diagnosis sensitivity of some diseases would increase. We might get several clues from these oxidative damage biomarkers and they are worth being studied as biomarkers for detection of diseases. Moreover, 8-oxodG/8-oxoG may provide us a new point of view to new drug research and development for these oxidativestress-mediated diseases. However, occurrence and development of diseases are attributed to multiple factors. Oxidative nucleic acid damage may be one of the links in this program, and other unknown parts still needing further deeply exploration. At present, the clinical application of 8-oxodG/8-oxoG is still in early stage study, and these studies are lack of reasonable prospective design and placebo control. In future, we should conduct more longterm, large-scale randomized control studies, confirming the concrete relationship between 8-oxodG/8-oxoG and the onset, course, development and prognosis of diseases.

\section{ACKNOWLEDGMENTS}

The authors gratefully acknowledge the financial support from the Natural Science Foundation of China (21402172, 81472666, 21602200), the Key Projects in the National Science \& Technology Pillar Program during the Twelfth Five-year Plan Period (2014BAI09B07), Natural Science Foundation of Zhejiang Province (LQ17H160012), Foundation of Education Department of Zhejiang Province (Y201636729), and Zhejiang Medical and Health Science and Technology Plan Project (2017KY373).

\section{CONFLICTS OF INTEREST}

All authors declare no conflicts of interest.

\section{REFERENCES}

1. Valavanidis A, Vlachogianni T, Fiotakis C. 8-Hydroxy2'-deoxyguanosine (8-OHdG): A critical biomarker of oxidative stress and carcinogenesis. J Environ Sci Health C Environ Carcinog Ecotoxical Rev. 2009; 27:120-139.

2. Cooke MS, Evans MD, Dove R, Rozalski R, Gackowki D, Siomek A, Lunec J, Olinski R. DNA repair is responsible for the presence of oxidatively damaged DNA lesions in urine. Mutat Res. 2005; 574:58-66.

3. Evans MD, Dizdaroglu M, Cooke MS. Oxidative DNA damage and disease: induction, repair and significance. Mutat Res. 2004; 567:1-61.

4. Kehrer JP. Free radicals as mediators of tissue injury and disease. Crit Rev Toxicol. 1993; 23:21-48.

5. Guo C, Li X, Wang R, Yu J, Ye M, Mao L, Zhang S, Zheng S. Association between oxidative DNA damage and risk of colorectal cancer: sensitive determination of urinary 8-hydroxy-2'-deoxyguanosine by UPLC-MS/MS analysis. Sci Rep. 2016; 6:32581.

6. Fleming AM, Alshykhly OR, Zhu J, Muller JG, Burrows CJ. Rates of chemical cleavage of DNA and RNA oligomers containing guanine oxidation products. Chem Res Toxicol. 2015; 28:1292-1300.

7. Peterson DA, Gerrard JM. Evidence that the peroxidase of the fatty acid cyclooxygenase acts via a fenton type of reaction. Prostaglandins Leukot Med. 1983; 12:73-76.

8. Menon R. Oxidative stress damage as a detrimental factor in preterm birth pathology. Front Immunol. 2014; 5:567.

9. Valko M, Izakovic M, Mazur M, Rhodes CJ, Telser J. Role of oxygen radicals in DNA damage and cancer incidence. Mol Cell Biochem. 2004; 266:37-56.

10. Nunomura A, Moreira PI, Takeda A, Smith MA, Perry G. Oxidative RNA damage and neurodegeneration. Curr Med Chem. 2007; 14:2968-2975.

11. Fimognari C. Role of oxidative RNA damage in chronicdegenerative diseases. Oxid Med Cell Longev. 2015; 2015:358713.

12. Henle ES, Linn S. Formation, prevention, and repair of DNA damage by iron/hydrogen peroxide. J Biol Chem. 1997; 272:19095-19098.

13. Kong Q, Lin CL. Oxidative damage to RNA: mechanisms, consequences, and diseases. Cell Mol Life Sci. 2010; 67:1817-1829.

14. Kasai, H. Analysis of a form of oxidative DNA damage, 8-hydroxy-2'-deoxyguanosine, as a marker of cellular oxidative stress during carcinogenesis. Mut Res. 1997; 387:147-163.

15. Evans MD, Saparbaev M, Cooke MS. DNA repair and the origins of urinary oxidized 2'-deoxyribonucleosides. Mutagenesi. 2010; 25:433-442.

16. Cooke MS, Evans MD, Dove R, Rozalski K, Gackowski D, Siomerk A, Lunec J, Olinski R. DNA repair is responsible for the presence of oxidatively damaged DNA lesions in urine. Mutat Res. 2005; 574:58-66.

17. Jaruga P, Dizdaroglu M. Repair of products of oxidative DNA base damage in human cells. Nucleic Acid Res. 1996; 24:1389-1394. 
18. Wurtmann EJ, Wolin SL. RNA under attack: cellular handling of RNA damage. Crit. Rev. Biochem Mol Biol. 2009; 44:34-49.

19. Cooke MS, Evans MD, Dizdaroglu M, Lunec J. Oxidative DNA damage: mechanisms, mutation and disease. FASEB J. 2003; 17:1195-1214.

20. Dincer Y, Erzin Y, Himmetoglu S, Gunes KN, Bal K, Akcay T. Oxidative DNA damage and antioxidant activity in patients with inflammatory bowel disease. Dig Dis Sci. 2007; 52:1636-1641.

21. Sato T, Takeda H, Otake S, Yokozawa J, Nishise S, Fujishima S, Orii T, Fukui T, Takano J, Sasaki Y. Increased plasma levels of 8-hydroxydeoxyguanosine are associated with development of colorectal tumors. J Clin Biochem Nutr. 2010; 47:59-63.

22. Chang D, Wang F, Zhao YS, Pan HZ. Evaluation of oxidative stress in colorectal cancer patients. Biomed Environ Sci. 2008; 21:286-289.

23. Rozalski R, Gackowski D, Siomek-Gorecka A, Starcazk M, Modrzejewicz Z, Olinski R. Urinary 5-hydroxymethyluracil and 8-oxo-7,8-dihydroguanine as potential biomarkers in patients with colorectal cancer. Biomarkers. 2015; 20:287-291.

24. Papa A, Danese S, Sgambato A, Ardito R, Zannoni G, Vecchino FM, Gentiloni-Silveri N, Cittadini G, Gasbarrini A. Role of helicobacter pylori CagA + infection in determining oxidative DNA damage in gastric mucosa. Scand J Gastroenterol. 2002; 37:409-413.

25. Kawanishi S, Ohnishi S, Ma N, Hiraku Y, Oikawa S, Murata M. Nitrative and oxidative DNA damage in infectionrelated carcinogenesis in relation to cancer stem cells. Genes Environ. 2017; 38:26.

26. Ni J, Mei M, Sun L. Oxidative DNA damage and repair in chronic atrophic gastritis and gastric cancer. Hepatogastroenterology. 2012; 59:671-675.

27. Kauppi J, Räsänen J, Sihvo E, Nieminen U, Arkkila P, Ahotupa M, Salo J. Increased oxidative stress in the proximal stomach of patients with barrett's esophagus and adenocarcinoma of the esophagus and esophagogastric Junction. Transl Oncol. 2016; 9:336-339.

28. Ma Y, Zhang L, Rong S, Qu H, Zhang Y, Chang D, Pan H, Wang W. Relation between gastric cancer and protein oxidation, DNA damage, and lipid peroxidation. Oxid Med Cell Longev. 2013; 2013:543760.

29. Ock CY, Kim DJ, Choi DJ, Hahm KB, Chung MH. 8-Hydroxydeoxyguanosine: not mere biomarker for oxidative stress, but remedy for oxidative stress-implicated gastrointestinal diseases. World J Gastroentral. 2012; 18:302-308.

30. Dincer Y, Himmetoglu S, Akcay T, Ersoy EY, Gunes KN, Tortum O. Prognostic significances of oxidative DNA damage evaluated by 8-hydroxy-deoxyguanosine and antioxidant enzymes in patients undergoing resection of gastric and colon carcinoma. Neoplasma. 2007; 54:131-136.
31. Poulsen HE, Prieme H, Loft S. Role of oxidative DNA damage in cancer initiation and promotion. Eur J Cancer Prev. 1998; 7:9-16.

32. Cho SH, Choi MH, Lee WY, Chung BC. Evaluation of urinary nucleosides in breast cancer patients before and after tumor removal. Clin Biochem. 2009; 42:540-543.

33. Kuo HW, Chou SY, Hu TW, Wu FY, Chen DJ. Urinary 8-hydroxy-2'-deoxyguanosine (8-OHdG) and genetic polymorphisms in breast cancer patients. Mutat Res. 2007; 631:62-68.

34. Guo C, Li X, Ye M, Xu F, Yu J, Xie C, Cao X, Guo M, Yuan Y, Zheng S. Discriminating patients with early-stage breast cancer from benign lesions by detection of oxidative DNA damage biomarker in urine. Oncotarget. 2017; 8:53100-53109. https://doi.org/10.18632/oncotarget.17831.

35. Sova H, Jukko-Vuorinen A, Puistola U, Kauppila S, Karihtala P. 8-Hydroxydeoxyguanosine: a new potential independent prognostic factor in breast cancer. $\mathrm{Br} \mathrm{J}$ Cancer. 2010; 102:1018-1023.

36. Jakovcevic D, Dedic-Plavetic N, Vrbanec D, Jakovcevic A, Jakic-Razumovic J. Breast cancer molecular subtypes and oxidative DNA damage. Appl Immunohistochem Mol Morphol. 2015; 23:696-703.

37. Filaire E, Dupuis C, Galvaing G, Aubreton S, Laurent H, Richard R, Filaire M. Lung cancer: what are the links with oxidative stress, physical activity and nutrition. Lung Cancer. 2013; 82:383-389.

38. Shen J, Deininger P, Hunt JD, Zhao H. 8-Hydroxy2'-deoxyguanosine (8-OHdG) as a potential survival biomarker in patients with non-small-cell lung cancer. Cancer. 2007; 109:574-580.

39. Pylvas M, Puistola U, Laatio L, Kauppila S, Karihtala P. Elevated serum 8-OHdG is associated with poor prognosis in epithelial ovarian cancer. Anticancer Res. 2011; 31:1411-1415.

40. Khadem-Ansari MH, Shahsavari Z, Rasmi Y, Mahmoodlo R. Elevated levels of urinary 8-hydroxy-2'-deoxyguanosine and 8-isoprostane in esophageal squamous cell carcinoma. J Carcinog. 2011; 10:14.

41. Nunomura A, Hofer T, Moreira PI, Castellani RJ, Smith MA, Perry G. RNA oxidation in Alzheimer diseases and related neurodegenerative disorders. Acta Neuropathol. 2009; 118:151-166.

42. Nunomura A, Perry G, Pappolla MA, Wade R, Hirai K, Chiba S, Smith MA. RNA oxidation is a prominent feature of vulnerable neurons in Alzheimer's disease. J. Neurosci. 1999; 19:1959-1964.

43. Hofer T, Perry G. Nucleic acid oxidative damage in Alzheimer's disease-explained by the hepcidin-ferroportin neuronal iron overload hypothesis? J Trace Elem Med Biol. 2016; 38:1-9.

44. Nunomura A, Tamaoki $\mathrm{T}$, Tanaka $\mathrm{K}$, Motohashi N, Nakamura M, Hayashi T, Yamaguchi H, Shimohama S, Lee 
HG, Zhu XW, Smith MA, Perry G. Intraneuronal amyloid beta accumulation and oxidative damage to nucleic acids in Alzheimer disease. Neurobiol Dis. 2010; 37:731-737.

45. Lovell MA, Gabbita SP, Markesbery WR. Increased DNA oxidation and decreased levels of repair products in Alzheimer's disease ventricular CSF. J Neurochem. 1999; 72:771-776.

46. Isobe $\mathrm{C}, \mathrm{Abe} \mathrm{T}$, Terayama $\mathrm{Y}$. Homocysteine may contribute to pathogenesis of RNA damage in brains with Alzheimer's disease. Neurodegener Dis. 2009; 6:252-257.

47. Shan X, Lin CL. Quantification of oxidized RNAs in Alzheimer's disease, Neurobiol Aging. 2006; 27:657-662.

48. Ding Q, Zhu H, Zhang B, Soriano A, Burns R, Markesbery WR. Increased 5S rRNA oxidation in Alzheimer's disease. J Alzheimers Dis. 2012; 29:201-209.

49. Wang J, Xiong S, Xie C, Markesbery WR, Lovell MA. Increased oxidative damage in nuclear and mitochondrial DNA in Alzheimer's disease. Neurochem. 2005; 93:953-962.

50. Sander LG, Greenamyre JT. oxidative damage to macromolecules in human Parkinson disease and rotenone model. Free Radic Biol Med. 2013; 62:111-120.

51. Abe T, Isobe C, Murata T, Sato C, Tohgi H. Alteration of 8-hydroxyguanosine concentrations in the cerebrospinal fluid and serum from patients with Parkinson's disease. Neurosci Lett. 2003; 336:105-108.

52. Kikuchi A, Takeda A, Onodera H, Kimpara T, Hisanaga K, Sato N, Sato N, Nunomura A, Castellani RJ, Perry G, Smith MA, Itoyama Y. Systemic increase of oxidative nucleic acid damage in Parkinson's disease and multiple system atrophy. Neurobiol Dis. 2002; 9:244-228.

53. Yasuhara T, Hara, K, Sethi KD, Morgan JC, Borlongan CV. Increased 8-OHdG levels in the urine, serum, and substantia nigra of hemiparkinsonian rats. Brain Res. 2006; 1133:49-52.

54. Aguiar CC, Almeida AB, Araújo PV, de Abreu RN, Chaves EM, do Vale OC, Macêdo DS, Woods DJ, Fonteles MM, Vasconcelos SM. Oxidative stress and epilepsy: literature review. Oxid Med Cell Longev. 2012; 2012:795259.

55. Rumià $\mathrm{J}$, Marmol $\mathrm{F}$, Sanchez $\mathrm{J}$, Giménez-Crouseilles $\mathrm{J}$, Carreño M, Bargalló N, Boget T, Pintor L, Setoain X, Donaire A, Saez GT, Ribalta T, Ferrer E, et al. Oxidative stress markers in the neocortex of drug-resistant epilepsy patients submitted to epilepsy surgery. Epilepsy Res. 2013; 107:75-81.

56. Navarro A, Boveris A, Bández MJ, Sánchez-Pino MJ, Gómez C, Muntané G, Ferrer I. Human brain cortex: mitochondrial oxidative damage and adaptive response in Parkinson disease and in dementia with Lewy bodies. Free Radic Biol. Med. 2009; 46:1574-1580.

57. Lyras L, Perry RH, Perry EK, Ince PG, Jenner A, Jenner P, Halliwell B. Oxidative damage to proteins, lipids, and DNA in cortical brain regions from patients with dementia with Lewy bodies. J Neurochem. 1998; 71:302-312.
58. Brown DR. Neurodegeneration and oxidative stress: prion disease results from loss of antioxidant defence. Folia Neuropathol. 2005; 43:229-243.

59. Guentchev M, Siedlak SL, Jarius C, Tagliavini F, Castellani RJ, Perry G, Smith MA, Budka H. Oxidative damage to nucleic acids in human prion disease. Neurobiol Dis. 2002; 9:275-281.

60. Chang Y, Kong Q, Shan X, Tian G, Ilieva H, Cleveland DW, Rothstein JD, Borchelt DR, Wong PC, Lin CL. Messenger RNA oxidation occurs early in disease pathogenesis and promotes motor neuron degeneration in ALS. PLoS One. 2008; 3:e2849.

61. Wei YC, Zhou FL, He DL, Bai JR, Ding H, Wang XY, Nan KJ. Oxidative stress in depressive patients with gastric adenocarcinoma. Int J Neuropsychopharmacol. 2009; 12:1089-1096.

62. Al-Aubaidy H, Jelinek H. Oxidative DNA damage and obesity in type 2 diabetes mellitus. Eur J Endocrinol. 2011; 164:899-904.

63. Zengi A, Ercan G, Caglayan O, Tamsel S, Karadeniz M, Simsir I, Harman E, Kahraman C, Orman M, Cetinkalp $\mathrm{S}$, Ozgen G. Increased oxidative DNA damage in lean normoglycemic offspring of type 2 diabetic patients. Exp Clin Endocrinol Diabetes. 2011; 119:467-471.

64. Nishikawa T, Sasahara T, Kiritoshi S, Sonoda K, Senokuchi T, Matsuo T, Kukidome D, Wake N, Matsumura T, Miyamura N, Sakakida M, Kishikawa H, Araki E. Evaluation of urinary 8-hydroxydeoxy-guanosine as a novel biomarker of macrovascular complications in type 2 diabetes. Diabetes Care. 2003; 26:1507-1512.

65. Kim J, Kim CS, Sohn E, Jeong IH, Kim H, Kim JS. Involvement of advanced glycation end products, oxidative stress and nuclear factor-kappaB in the development of diabetic keratopathy. Graefes Arch Clin Exp. Ophthalmol. 2011; 249:529-536.

66. Braunwald E. Biomarkers in heart failure. Preface Heart Fail Clin. 2009; 5:xiii-xiv.

67. Xiang F, Shuanglun X, Jingfeng W, Ruqiong N, Yuan Z, Yongqing L, Jun Z. Association of serum 8-hydroxy-2'deoxyguanosine levels with the presence and severity of coronary artery disease. Coron Artery Dis. 2011; 22:223-227.

68. Nagayoshi Y, Kawano H, Hokamaki J, Uemura T, Soejima H, Kaikita K, Sugiyama S, Yamabe H, Shioji I, Sasaki S, Kuroda Y, Ogawa H. Differences in oxidative stress markers based on the aetiology of heart failure: comparison of oxidative stress in patients with and without coronary artery disease. Free Radic Res. 2009; 43:1159-1166.

69. Kroese LJ, Scheffer PG. 8-hydroxy-2'-deoxyguanosine and cardiovascular disease: a systematic review. Curr Atheroscler Rep. 2014; 16:452.

70. Kobayashi S, Susa T, Tanaka T, Wada Y, Okuda S, Doi M, Nao T, Yoshiga Y, Yamada J, Okamura T, Ueyama T, Kawamura S, Yano M, et al. Urinary 8-hydroxy-2'- 
deoxyguanosine reflects symptomatic status and severity of systolic dysfunction in patients with chronic heart failure. Eur J Heart Fail. 2011; 13:29-36.

71. Susa T, Kobayashi S, Tanaka T, Murakami W, Akashi S, Kunitsugu S, Okuda S, Doi M, Wada Y, Nao T. Urinary 8 -hydroxy-2'-deoxyguanosine as a novel biomarker for predicting cardiac events and evaluating the effectiveness of carvedilol treatment in patients with chronic systolic heart failure. Circ J. 2012; 76:117-126.

72. Arumugam P, Ramesh S. Protective effects of sesame oil on 4-NQO-induced oxidative DNA damage and lipid peroxidationin rats. Drug Chem Toxicol. 2011; 34:116-119.

73. Khan N, Syed DN, Ahmad N, Mukhtar H. Fisetin: a dietary antioxidant for health promotion. Antioxid Redox Signal. 2013; 19:151-162.

74. Gutierrez-Mariscal FM, Perez-Martinez P, Delgado-Lista J, Yubero-Serrano EM, Camargo A, Delgado-Casado N, CruzTeno C, Santos-Gonzalez M, Rodriguez-Cantalejo F, Castaño JP, Villalba-Montoro JM, Fuentes F, Perez-Jimenez F, et al. Mediterranean diet supplemented with coenzyme Q10 induces postprandial changes in p53 inresponse to oxidative DNA damage in elderly subjects. Age. 2012; 34:389-403.

75. Pandya CD, Howell KR, Pillai A. Antioxidants as potential therapeutics for neuropsychiatric disorders. Prog Neuropaychopharmacol Biol Psychiatry. 2013; 46:214-223.

76. Amararathna M, Johnston MR, Rupasinghe HP. Plant polyphenols as chemopreventive agents for lung cancer. Int J Mol Sci. 2016; 17:17081352.

77. Bjelakovic G, Nikolova D, Simonetti RG, Gluud C. Systematic review: primary and secondary prevention of gastrointestinal cancers with antioxidant supplements. Aliment Pharmacol Ther. 2008; 28:689-703.

78. Kim JH, Xu EY, Sacks DB, Lee J, Shu L, Xia B, Kong AN. Identification and functional studies of a new Nrf2 partner IQGAP1: a critical role in the stability and transactivation of Nrf2. Antioxid Redox Signal. 2013; 19:89-101.

79. Bjelakovic G, Nikolova D, Simonetti RG, Gluud C. Antioxidant supplements for prevention of gastrointestinal cancers: a systematic review and meta-analysis. Lancet. 2008; 28:1219-1228.

80. Noguchi T, Kobayashi J, Yagi K, Nohara A, Yamaaki $\mathrm{N}$, Sugihara M, Ito N, Oka R, Kawashiri MA, Tada H, Takata M, Inazu A, Yamagishi $\mathrm{M}$, et al. Comparison of effects of bezafibrate and fenofibrate on circulating proprotein convertase subtilisin/kexin type 9 and adipocytokine levels in dyslipidemic subjects with impaired glucose tolerance or type 2 diabetes mellitus: Results from a crossover study. Atherosclerosis. 2011; 217:165-170.

81. Park KS, Kim JH, Kim MS, Kim SK, Choi JY, Chung MH, Han B, Kim SY, Lee HK. Effects of insulin and antioxidant on plasma 8-hydroxyguanine and tissue 8-hydroxydeoxyguanosine in streptozotocin-induced diabetic rats. Diabetes. 2001; 50:2837-2841.

82. Igarashi $M$, Watanabe $M$, Yoshida $M$, Sugaya $K$, Endo Y, Miyajima N, Abe M, Sugano S, Nakae D.
Enhancement of lung carcinogenesis initiated with 4-(N-hydroxymethylnitrosamino)-1-(3-pyridyl)-1-butanone by Ogg1 gene deficiency in female, but not male, mice. J Toxicol Sci. 2009; 34:163-174.

83. Liu C, Bronson RT, Russell RM, Wang XD. $\beta$-Cryptoxanthin supplementation prevents cigarette smoke-induced lung inflammation, oxidative damage and squamous metaplasia in ferrets. Cancer Prv Res. 2011; 4:1255-1266.

84. Nakamura T, Tanaka S, Hirooka K, Toyoshima T, Kawai N, Tamiya T, Shiraga F, Tokuda M, Keep RF, Itano T, Miyamoto O. Anti-oxidative effects of d-allose, a rare sugar, on ischemia-reperfusion damage following focal cerebral ischemia in rat. Neurosci Lett. 2011; 487:103-106.

85. Zhang ZY, Sun BL, Yang MF, Li DW, Fang J, Zhang S. Carnosine attenuates early brain injury through its antioxidative and anti-apoptotic effects in a rat experimental subarachnoid hemorrhage model Cell Mol Neurobiol. 2015; 35:147-157.

86. Nito C, Ueda M, Inaba T, Katsura K, Katayama Y. FK506 ameliorates oxidative damage and protects rat brain following transient focal cerebralischemia. Neurol Res. 2011; 33:881-889.

87. Suda S, Katsura K, Kanamaru T, Saito M, Katayama Y. Valproic acid attenuates ischemia-reperfusion injury in the rat brain through inhibition of oxidative stress and inflammation. Eur J Pharmacol. 2013; 707:26-31.

88. Oyama J, Maeda T, Sasaki M, Kozuma K, Ochiai R, Tokimitsu I. Green tea catechins improve human forearm vascular function and have potent anti-inflammatory and anti-apoptotic effects in smokers. Intern Med. 2010; 49:2553-2559.

89. Tain YL, Huang LT, Lin IC, Lau YT, Lin CY. Melatonin prevents hypertension and increased asymmetric dimethylarginine in young spontaneous hypertensive rats. J Pineal Res. 2010; 49:390-398.

90. Song MF, Li YS, Ootsuyama Y, Kasai H, Kawai K, Ohta M, Eguchi Y, Yamato H, Matsumoto Y, Yoshida R, Ogawa Y. Urea, the most abundant component in urine, cross-reacts with a commercial 8-OH-dG ELISA kit and contributes to overestimation of urinary 8-OH-dG. Free Radic Biol Med. 2009; 47:41-46.

91. Wang CC, Chen WL, Lin CM, Lai CH, Loh CH, Chen HI, Liou SH. The relationship between plasma and urinary 8-hydroxy-2-deoxyguanosine biomarkers measured by liquid chromatography tandem mass spectrometry. Environ Sci Pollut Res Int. 2016; 23:17496-17502.

92. Li MJ, Zhang JB, Li WL, Chu QC, Ye JN. Capillary electrophoretic determination of DNA damage markers: content of 8-hydroxy-2'-deoxyguanosine and 8-nitroguanine in urine. J. Chromatogr. B. Analyt. Technol Biomed Life Sci. 2011; 879:3818-3822.

93. Inaba Y, Koide S, Yokoyama K, Karube I. Development of urinary 8-hydroxy-2'-deoxyguanosine (8-OHdG) measurement method combined with SPE. J Chromatogr Sci. 2011; 49:303-309. 